mushroom. They likened the effect to published photographs of atomic bomb explosions and considered it was larger than any thunder cloud they had ever seen. No estimate of the distance was possible. The colour was white at first, later turning yellow-orange. At this stage they had to turn southwards and could not look backwards.

In turning, they noticed the temperature changed by 6 deg. C. Investigation revealed that an upperair temperature observation at Keflavik, Iceland, at 3 a.m. on the same day included an unusual increase of temperature (inversion) by 4 deg. C. between 43,500 and 45,000 ft., well in the stratosphere, and that the wind distribution was such that this inversion would have reached the position of the aircraft at the time of the observation. Further, cumulonimbus clouds (towering thunder clouds) were observed at stations on the north-west coast of Norway during the morning.

From this it is concluded that the aircraft flew through the inversion and that the abnormal refraction within the inversion produced the distorted vision of these distant clouds. Photographs very similar in appearance of the Bavarian Alps have been taken in known inversion conditions from a peak in the Black Forest. Few similar observations have been reported by aircraft crews, unless some so-called 'flying saucer' reports have such a phenomenon as their basis, and certainly none from so great a height.

The Meteorological Office would welcome additional aircraft reports, especially for the light they would throw on the existence of unusual thermal structure at great heights.

\section{ORDINARY FAMILIES AND THE SOCIAL SERVICES}

$\mathrm{W}$

ITH the financial assistance of the Nuffield Foundation, Political and Economic Planning is undertaking an investigation into the impact of the social services in Britain upon ordinary families. A pilot survey has already been made, and, in view of the importance of the findings, PEP has decided to make these available bofore the main survey is completed*.

The original proposal for the inquiry grew out of the considerable amount of research already carried out by PEP on different aspects of social welfare policy. 'This indicated that the time had come when further assessment of the working of the different services would be helped by a survey aimed at collecting information on the attitude of consumers to the services and on the extent to which their needs are being satisfied or overlooked.

In order to make the group studied reasonably homogeneous, only families with children were included in the survey. The inquiry was made into conditions affecting ordinary families and did not concentrate upon families in special difficulties, even though such families may be heavy claimants on the social services.

The basic purpose of the inquiry was to throw light on the extent to which it is felt that the needs of ordinary families have been met as well as to provide information on the role of the social services in family life. * Planning. Vol. 22, No. 403 (8 October 1956) : Ordinary Families
and the Social Services-Piloting an knquiry. Pp. 189-204. (London : Political and Economic Planning, 1956.) 2s. $6 d$.
An early step in the inquiry was to consult social workers to discuss the occasions when the different social services were likely to be used by ordinary families. Preliminary interviews were then carried out with some families in which discussion was based upon the points which had been formulated by this means ; but no formal questionnaire was used. The interviews were long and all the situations relevant to use of the social services were discussed, ranging from childbirth to care of the aged. These interviews provided case-study material and showed that it was possible to find out the kind of use made of these services by a particular family.

Increased concern for the interests of the family as a whole has been one of the features of social thought in recent years. Attention has been directed to gaps in the working of welfare services and to overlapping or division of function leading to inefficiency in action. In spite of the wide range of statutory services it is still possible for families to get into difficulties which threaten their stability. The PEP inquiry sought to find out whether families had had difficulty in using particular services or were conscious of occasions when they had needed help but had not obtained it.

The extension of the statutory social services in the post-war years has led to some concern lest people should be encouraged to seek help outside the family circle, with a consequent lessening of personal sense of responsibility. It is believed by some that people are now looked after from the cradle to the grave, and that the Welfare State is the final realization of the aims of social reformers. It is also believed that the community has gone too far in taking over responsibility formerly left to families and individuals; that the cost of the social services bears too hard upon certain sections of the population; and that the present system of universal benefits is not needed in conditions of full employment and a high standard of living. The inquiry hoped to find out how far these attitudes are reflected in the opinions of ordinary families.

For the pilot inquiry, the main need was to interview as quickly as possible a large enough number of families to be able to judge whether the information could be obtained and handled as planned. Certain areas were chosen for convenience of interviewing in three different London boroughs, and random calls were made and interviews carried out wherever there was a mother with children in the house available for interview. In all, ninety mothers have been interviewed so far, and two fathers. There have been very few refusals. Interviews all took at least an hour, and sometimes two.

So far the inquiry has been entirely exploratory. Questions have been asked to obtain the following information :

How do mothers regard the help they receive? Do they feel their families are helped a great deal or not very much ? Of which parts of the social services are they most aware? Is there a Welfare State attitude? What form does it take? How does the feeling of different sections vary? Which are the most important services? With which do families and mothers have a lot of contact? What differences are there between different sections of the population in contact with the services? Which services are considered to have worked well ? How do people view the amount of help given? To what extent is there failure to obtain any service needed and how does it arise? What difficulties are experienced ? How have families managed in particular situations of difficulty ? 
What resources of help have they used ? What degree of difficulty do they consider they have had? What problems do families face at the moment? What services might be concerned ? Do some families have problems which might be relevant to more than one service?

The inquiries showed that, while there were many peculiar impressions about the different kinds of social services and how they were paid for, on the whole people had a clear idea of how they were financed, what the benefits were, and appreciated them. To take a measure of the success of the services, mothers were asked what they thought of the help they had received when they had last had contact with each service. They were also asked more detailed questions about their experience of some services.

Comments on the help given by the doctor showed $a_{a}$ high degree of appreciation and also indicated what kind of things appreciation was based on ; these were mainly connected with the personal attention given by the doctor. The general attitude towards treatment received at hospitals was also extremely favourable. There were, however, a few more critical comments, particularly in connexion with the outpatient service. Most of these were complaints about waiting, but some were about treatment; others were about conditions in which the treatment was given.

Many of the families with children under five were using welfare centres, but some were not. Most mothers using the centres thought them very useful, but some comments of a different kind were made; complaints were usually that the centre was too far from their homes. The maternity grant was generally regarded as useful although it was thought to have little relation to the expense of confinement. In some cases the wife had worked beforehand to prepare for the expenses of this occasion and to provide a supplement to the grant. The attitude towards home confinement allowance was rather the same.

Most of the families who had drawn sickness benefit had had to rely upon additional resources of some kind. The part played by the benefit itself in meeting the cost of the family when the breadwinner was ill does not seem to have been as great as is generally believed. Many cases were found where the money had boen made up by the husband's firm. Fxtra sources of help mentioned were club money, savings, borrowed money. wife's earnings, and so on.

Very many of the families interviewed had tried at some time to get help with a housing problem, and many of them still had their names down on housing lists; many had been unsuccessful. Some families had managed to help themselves, and this was remarked on somewhat ruefully since the chance of obtaining a council house had thereby been lost. Several families considered that housing was their chief problem.

As the mothers were shown each list of services they were asked whether they could remember any occasion when one or other of their family had needed a particular service but for some reason had not been able to get it. The information resulting from this question was considered together with answers to specific questions about how they had in fact managed when the mother was ill, for example, or when the father was at home from work, or some other crisis had occurred.

Most of the families had had to cope with situations when the mother was ill through confinement and had managed with the help of friends and relatives. In several cases the husband had stayed at home from work, either taking annual leave or taking time off.

One of the purposes of the design of the survey had been not only to ask about the use of the different social services, but also to get a picture of the range of problems which families were facing. Some of the families had problems which were relevant to more than one of the social services.

The purpose of the pilot survey was to show what kind of material could be collected, and how to collect it. It did not attempt to collect sufficient data to provide the answers to the questions posed. This will be the task of the main inquiry. It is proposed that a random sample of something like a thousand families with children should be interviewed in a particular area.

\section{EXPERIMENTS IN GROUP CONFLICT}

CONFLICT between groups is often rooted deep $A$ in personal, social, economic, religious and his. torical forces. Inter-group conflict and harmony is not a subject that lends itself easily to laboratory experiments, and in recent years there have been attempts to investigate the problem under controlled yet life-like conditions.

A series of experimental studies was begun by Muzafer Sherif and his colleagues in 1948 and are still continuing. What the limited experiments have so far shown is described in The Scientific American (November 1956).

It was decided to conduct the study with groups of an informal type, where group organization and attitudes would evolve naturally and spontaneously. For this purpose an isolated summer camp was chosen as a good experimental setting; and boys about eleven or twelve years old who would find camping natural and fascinating were selected as subjects. The boys were of homogeneous background and did not know one another before they went to the camp.

None of the boys was aware that he was part of an experiment on group relations; the investigators appeared as a regular camp staff. To keep the situation as lifelike as possible, experiments were carried out within the framework of regular camp activities and games. Projects were set up which were so interesting and attractive that the boys plunged into them enthusiastically without suspecting that they might be test situations.

Observations were first made to show how the boys became a coherent group. As was to be expected, they quickly formed particular friendships and chose 'buddies'. In a few days the boys were divided into two groups and put into different cabins. Before this happened each boy was asked informally who his best friends were, and then 'best friends' were placed in different groups so far as possible.

A group of strangers brought together in some common activity soon acquires an informal and spontaneous kind of organization. It comes to look upon some members as leaders, divides up duties, adopts unwritten norms of behaviour, and develops an esprit de corps. These boys followed this pattern as they shared a series of experiences. In each group the boys pooled their efforts, organized duties and 